\title{
ABEn SERGIPE: 47 ANOS DE LUTA E RESISTÊNCIA'
}

\author{
THE BRAZILIAN ASSOCIATION OF NURSING (ABEn) IN THE FEDERAL \\ STATE OF SERGIPE: 47 YEARS OF STRUGGLE AND RESISTENCE \\ ABEN SERGIPE: 47 AÑOS DE LUCHA Y RESISTENCIA
}

\author{
Maria Jésia Vieirá \\ Cassia Maria Macedo Silva Faro ${ }^{3}$
}

\begin{abstract}
RESUMO: o trabalho relata os fatos que contribuiram para a criação da seção Sergipe da ABEn, sua trajetória, sua contribuição na formação da imagem cultural da profissão na sociedade sergipana, e suas principais realizações, tais como participação na criação e organização de serviços e instituições. Fala também de suas dificuldades, mas principalmente da luta constante para persistir mantendo seus princípios, seu papel na organização social e cultural da classe, e no serviço à comunidade.
\end{abstract}

PALAVRAS-CHAVE: história da enfermagem, ABEn, organização em enfermagem

A história da ABEn Sergipe (ABEn-SE, 1958-1970, 1985-2001) está intimamente ligada à história da Enfermagem e da Saúde em Sergipe.

Fatos e circunstâncias anteriores culminaram com a criação desta seção, que passou, então a coordenar, dai para adiante, os destinos, e até a vida social dos profissionais da Enfermagem no Estado.

Estes fatos e circunstâncias podem ser sistematizados, segundo pesquisas feitas, da forma como discorreremos a seguir:

Até o ano de 1931, a saúde em Sergipe se direcionava a ações de vigilância sanitária e combate a doenças pestilenciais.

A reorganização do Departamento Nacional de Saúde, na capital Federal, a criação da Escola de Enfermagem de DNSP, e a repercussão que estava tendo o serviço prestado por estas enfermeiras no combate às epidemias e na organização das Unidades de Saúde do Rio de Janeiro, fez com que outros Estados procurassem enfermeiros formados por esta Escola para integrarem os seus quadros.

Pelo decreto de 16 de maio de 1931 cria-se o Departamento de Saúde Pública de Sergipe, sendo seu coordenador o Dr. José Rodrigues Bastos Coelho, que conhecendo o trabalho das enfermeiras a nivel nacional, e incentivado pelo Dr. Simeão Vieira Sobral, começa a enviar, a partir de junho de 1931, jovens sergipanas para a Escola de Enfermagem Anna Nery, para que realizassem sua formação superior, e voltassem para organizar o Serviço de Saúde do Estado. A primeira enfermeira profissional do Estado de Sergipe foi D. Opelina Rolemberg, que após conclusão do seu curso foi convocada a integrar o quadro do Ministério da Saúde, no Rio de Janeiro, ficando à disposição da Escola Anna Nery, como instrutora de alunas, somente vindo para Sergipe em 25 de novembro de 1937, após insistentes solicitações do Departamento de

1 Conferência proferida durante a Semana da Enfermagem, em Sergipe, 2001.

2 Enfermeira, professora adjunta doutora do Departamento de Enfermagem e Nutrição do Centro de Ciências Biológicas e da Saúde da Universidade Federal de Sergipe.

3 Enfermeira, professora assistente mestra do Departamento de Enfermagem e Nutrição do Centro de Ciências Biológicas e da Saúde da Universidade Federal de Sergipe. 
Saúde Pública deste Estado, ao Ministério da Saúde e à Escola de Enfermagem Anna Nery. Aqui chegando, organizou o serviço de visitadoras sanitárias, treinando e coordenando, desde então, as principais ações de saúde, tendo posteriormente prestado serviços também no Estado de Alagoas, e retornando depois para esta capital.

Em outra vertente da história, registramos a criação, em 1926, do Hospital de Cirurgia, que em pouco tempo passou a ser um Hospital Geral, sob a coordenação do Dr. Augusto Leite, passando depois aquele a denominar-se Fundação Beneficente Hospital de Cirurgia. Em 1950 é criado neste mesmo Hospital uma Escola de Auxiliares de Enfermagem, tendo sido sua primeira diretora, Isabel Colquhoun Mac Intyre, por indicação do Serviço Especial de Saúde Pública, hoje FNS. Em maio de 1952, incorpora-se ao quadro de enfermeiros do Hospital a Enfermeira Carmem Siqueira Aguiar (Carmem Aguiar Novais), que passa também a fazer parte do trabalho de organização da Escola, sendo sua vice diretora. A Escola iniciou suas atividades em 15 de agosto de 1952

Neste mesmo ano o Serviço Especial de Saúde Pública - SESP (FNS) estabelecia um grande plano de assistência ao interior do Estado, encaminhando enfermeiras para este serviço.

Os fatos relatados, com a conseqüente vinda de outras enfermeiras para o Estado, levaram a que se manifestasse a necessidade da criação de uma associação que servisse de base técnica, social e organizativa para os profissionais.

Em 12/04/1954 o grupo de enfermeiras, presidida por Isabel C. Mac Intyre, diretora da EAE do Hospital de Cirurgia, cria a diretoria provisória da ABEn Sergipe com o fim de organizála e eleger sua diretoria. Um mês depois tomou posse a $1^{\text {a }}$ diretoria, tendo como presidente Opelina Rolemberg. Deste ponto em diante, a história da ABEn Sergipe se confunde com a história da Enfermagem em Sergipe, pois todas as iniciativas partiam ou se faziam acompanhar da Associação.

Percebe-se desde as primeiras atas que desde o início a ABEn tinha como preocupação o aprimoramento de seu quadro associativo e de todos os ocupacionais da enfermagem. Preocupava-se, também com a vida social de seus membros, apoiando, fazendo-se presente, seja às alegrias, congratulações, seja às doenças, prestando solidariedade. É frequente, citações em ata, de casamentos, nascimento de filhos, viagens de estudos e aperfeiçoamento, como também doenças de enfermeiros e seus familiares, solicitando-se dos colegas que visitassem, ou quando necessário, que se revezassem na assistência ao doente.

A Semana de Enfermagem sempre foi o ponto alto das atividades da ABEn Sergipe. Ano após ano, há registros de atividades científico-culturais visando o crescimento profissional do grupo: palestras, cursos, atividades sociais como festas, bailes, desfiles de moda, bem como uma oportunidade de divulgar a profissão. Há registro de organização de vitrines nas lojas de maior destaque no comércio da capital, tais como "Dernier Cri", "Casa Aurora", "Galeria Cruzeiro" e outras, no sentido de fazer o marketing e com isto mostrar à população as principais atividades, realizações e campos de ação da Enfermagem. Podemos dizer que estas ações nos primeiros tempos da $A B E n$, corresponde à divulgação que hoje fazemos nos Shopping Centers, para que a população conheça e valorize a profissão.

Outra ação registrada com muita ênfase refere-se às palestras que eram feitas nas escolas de segundo grau, de Aracaju, à respeito da profissão, no sentido de incentivar as jovens a escolhê-la. Muitas enfermeiras, hoje, se referem a estas palestras como a fonte de conhecimento da profissão que possibilitou a formação da imagem e a motivação para a escolha, como demonstram em suas manifestações: (Vieira, 1998)

Ela mostrava o lado humano, uma oportunidade que você tinha de servir ao próximo. Ao mesmo tempo ela misturava, profissão e religião. Era uma comunhão com Deus, que na realidade é bem diferente. Ela pintou uma profissão de sonho. Enão sei com o que me encantei e fui atrás desse sonho. Realizei, mas acabei descobrindo que ele não era tão 
cor de rosa quanto a gente imaginava... (Anete).

...então essas pessoas me serviram, assim de modelo... elas nem me conheciam, eu também não tinha aproximação com elas, mas só de ver e ouvir as pessoas falarem sobre o que elas falavam e faziam no hospital... "Elas fazem isso... fazem aquilo... (Aurora).

...As pessoas elogiavam, principalmente as professoras, que eram tidas como lideres, como comandantes de grupos de trabal ho. Então eu procurava me identificar com elas... 'um dia eu vou ser uma enfermeira como essas pessoas'... (Aurora).

Além desta orientação, as enfermeiras se dispunham a estabelecer os contatos com as Escolas de Enfermagem, no sentido de encaminharem as candidatas para a realização do concurso vestibular, bem como a orientação sobre o internato, já que teriam que residir fora de seu Estado.

Muitas foram as sergipanas a ingressarem na carreira a partir desta iniciativa das sócias da ABEn Sergipe.

Entretanto, a maioria delas não retornava ao seu Estado, conseguindo emprego nas cidades onde concluiam o seu curso. Muitas se projetaram em serviços, escolas, seções estaduais ou diretoria central das associações, coordenações de Serviços, sendo frequente, ainda hoje, o reencontro e a identificação de conterrâneas, em qualquer espaço onde haja enfermeiros. Enquanto isto, Sergipe carecia de profissionais, e os trazia, também de outros Estados.

Voltando às comemorações da semana de enfermagem, no que se refere ainda à produção científica, as enfermeiras, não só se preocupavam em apresentar trabalhos no âmbito da Associação, mas também, em divulgá-los na mídia. Registra-se, no Jornal "A Cruzada", de maior veiculação na época, 1959, dois trabalhos publicados por enfermeiras: "A enfermeira e seus conhecimentos técnicos, científicos e morais", e em outra edição, no mesmo ano, "Enfermagem no choque vascular periférico". Ambos os trabalhos foram escritos por Maria José dos Santos, havendo uma comissão encarregada de avaliar os trabalhos a serem publicados (ata ABEn-Se de 07.04.1959). Estes trabalhos eram, também, apresentados no Centro de estudos do Hospital Cirurgia, conjuntamente com trabalhos de outros profissionais de saúde.

Além disto, havia também uma enfermeira, Acácia Maria, que era radialista, e que tinha um programa na "Rádio Cultura", e que, não só divulgava a profissão, mas também, durante a Semana da Enfermagem, colocava o programa à disposição da ABEn-Se.

Havia comissões encarregadas de cada um destes trabalhos, ou seja: organizar as vitrines, organizar as palestras nas escolas, avaliar os trabalhos, etc.

Em relação às condições de trabalho e salários, há registros constantes de encaminhamentos de solicitações de enquadramento funcional dos enfermeiros a nivel estadual, acompanhando o movimento que era feito, também, a nível nacional, bem como visitas à Delegacia Regional do Trabalho no sentido de que fosse atendida a legislação quando da criação de cargos nas instituições. Em relação aos ambientes de trabalho eram feitos, também, oficios às instituições empregatícias, esclarecendo sobre a natureza do trabalho de enfermagem, e sobre o risco das longas jornadas de trabalho, bem como sobre o uso indevido do título de enfermeiro, posicionando-se quanto a avaliação quando da admissão de novos contratados.

Já em 1959 havia discussões sobre sindicalismo, e sobre a necessidade de criação de uma seção sindical no quadro daABEn. Várias palestras foram feitas, e o Congresso Brasileiro de Enfermagem, neste ano, teve como tema central sindicalismo.

Em 1961 a seção conseguiu a promulgação da lei estadual $n^{0} 1003$, que proíbe o uso indevido do título de enfermeiro, no Estado. Neste mesmo ano foi reconhecida como de utilidade 
pública (Carvalho, 1976).

Em 1962, após muitas gestões a nível nacional, a enfermagem foi finalmente enquadrada no nivel superior.

No período de 1965 a seção teve dificuldade de eleger uma presidente, tendo uma delas recusado assumir o cargo após eleita (motivo não registrado), fazendo-se a seguir uma outra eleição, onde assume a presidência Osa Maria Machado de Araújo, contra sua própria vontade. Durante esta gestão registra-se a doença, e a seguir o falecimento de Opelina Rolemberg, sua primeira presidente, em 05.04.1966, no Rio de Janeiro.

Na gestão seguinte, sendo presidente Carmem Aguiar Novais, houve diversas denúncias de pessoas que se faziam passar por enfermeiros, e a vigilância da seção foi redobrada nesse sentido.

Em 1967 desenvolve-se em todo o país a campanha para angariar fundos para a construção da sede da Aben Central, em Brasília, e a seção Sergipe se empenhou com muita garra neste movimento, conseguindo contribuição significativa, apesar do seu pequeno número de sócias. O período seguinte foi um período difícil para a ABEn Sergipe, pois a existência de 03 chapas concorrentes à sua diretoria fez com que houvesse disputas pessoais e formação de grupos concorrentes, o que levou muitos sócios a se afastarem da mesma.

Em abril de 1969, tendo D. Waleska Paixão se aposentado como diretora da Escola de Enfermagem Ana Nery, veio residir e fazer um trabalho voluntário em Sergipe, integrando-se, desde então ao quadro de sócias da ABEn, participando de seus trabalhos, e sendo, mais tarde eleita, também presidente da seção.

A demanda por enfermeiros crescia nos serviços de saúde, os enfermeiros eram sobrecarregados de atividades, havia carência de profissionais, ao tempo em que, dos que se deslocavam para fazer o curso em outros estados, poucos eram os que retornavam.

AABEn - Se iniciou então seus estudos e discussões com vistas à implantação de um curso de Enfermagem na Universidade Federal de Sergipe, o que contou com a aquiescência do então diretor da faculdade de Ciências Médicas da Universidade, muito embora houvesse posições contrárias no âmbito da própria associação. Foi formado um grupo de trabalho, que apresentou uma exposição de motivos, com base na carência de profissionais para os serviços de saúde do Estado, mas, também, na demanda de candidatos ao curso em outras escolas do país, fato comprovado por dados de quatro Escolas pesquisadas, onde havia, na época, um total de 84 estudantes procedentes do Estado de Sergipe.

Este estudo ia ao encontro de um levantamento feito pelo Ministério de Educação e Cultura, sobre mercado de trabalho para as várias profissões de saúde em todo o país, resultando então na autorização da criação do curso de Enfermagem, com 20 vagas, o que se deu em 17/ 09/1975, realizando seu primeiro vestibular em janeiro de 1976.

Até este momento, as ações profissionais eram fiscalizadas pelo antigo Conselho Estadual de Medicina e Farmácia.

Com a promulgação da lei que cria o sistema COFEN /CORENS, a ABEn - Se, da mesma forma como aconteceu nos outros Estados, foi constituída uma junta provisória com o fim de organizar o Conselho Regional de Enfermagem de Sergipe, e eleger sua primeira diretoria. A posse se deu em 30/10/1975, contando Sergipe naquela ocasião com 50 enfermeiros inscritos no sistema.

ABEn e COREN Sergipe trabalhavam então sob estreita colaboração, agora acrescido do Departamento de Enfermagem da UFS, e da Escola de Auxiliares de Enfermagem Augusto Leite, que tinha sido seu berço desde o início.

Os cursos, jornadas e outros eventos eram promovidos conjuntamente, havendo somação de esforços no sentido de melhoria da qualidade das ações desenvolvidas, e na reivindicação de melhorias e direitos conquistados.

A partir da década de 1980, inicia-se a nível nacional um movimento que visava democratizar 
a Associação, aproximá-la mais de sua base, ao mesmo tempo em que tentava desatrelá-la das instituições de poder, para garantir maior liberdade de ação. Este, denominado Movimento Participação, recebeu o apoio da grande maioria de sócios da ABEn Sergipe, que compôs sua chapa às eleições em curso dentro destes princípios. Por decorrência de problemas no envio dos resultados do processo eleitoral, este foi totalmente impugnado no Estado de Sergipe, como também acontecera em outros Estados onde houve ganho da chapa do Movimento Participação, e embora válido e legítimo o processo, a ABEn Central não reconhecia a nossa diretoria regional, assim como outras em iguais condições.

Isto causou enormes problemas, pois neste periodo realizava-se o $2^{\circ}$ Encontro Regional de Enfermagem do Nordeste, e eram recebidas constantes ameaças da diretoria Central de que nada se poderia realizar em nome da ABEn. A esta altura, com todo o comprometimento já assumido, resolveu-se enfrentar todas as ameaças e realizar o Encontro, de 24 a 27 de abril de 1985, que representou, não só na história da ABEn Sergipe um importante marco, mas também foi o Forum de articulação de representantes de diversos Estados para as propostas de resolução dos entraves a nivel central, o que aconteceu, no mesmo ano, na Assembléia de delegadas em Recife, de 17 a 22 de novembro.

É importante registrar que, pressionadas a realizar outra eleição, sob pena de não ter acesso à Assembléia Nacional de Delegados, onde aconteceriam as negociações, a ABEn Sergipe, num gesto de coerência e união, referendou, por aclamação a mesma diretoria anteriormente eleita, embora soubesse que sua presidente, Prof. Maria Augusta Silva Cruz, teria dificuldades de assumir o mandato, a esta altura, pelo fato de estar assumindo a Pro Reitoria de assuntos estudantis da Universidade Federal de Sergipe. Mesmo assim, deliberouse pela permanência de sua vice presidente eleita, tendo a diretoria, como um todo, assumido conjuntamente os encargos da seção.

A realização do ENFNORDESTE, além de ser um momento de crescimento do grupo, trazia, também, imbutido na pretensão da diretoria e outros sócios, a possibilidade de poder, após o mesmo, adquirir um imóvel que pudesse se transformar em sede própria da ABEn, já que a mesma nunca tivera seu espaço, vez que o reduzido número de sócios, diferentemente de Estados de maior população de profissionais, não possibilitava esta aquisição. Os fatos relatados inviabilizaram a captação de verbas de orgãos e Empresas, não sendo possivel, portanto, a realização do sonho.

A gestão seguinte, sob a presidência da Prof. Maria Jésia Vieira, caracterizou-se pelo incentivo à produção científica, pela apresentação de trabalhos e conferências durante a reunião mensal da ABEn, e conjuntamente com sua coordenadora da comissão de atividades científicas e documentação, Sra. Irene Alves de Deus, que foi a seguir a próxima presidente, foram promovidos cursos de metodologia do trabalho científico, produção de trabalhos, e a ABEn Sergipe teve o prazer de voltar do Congresso Brasileiro de Enfermagem de 1989, em Belém do Pará, ostentando dois prêmios a nível nacional pela qualidade dos trabalhos científicos apresentados. Os trabalhos premiados foram: Riscos ocupacionais em UTI X proteção especifica, de autoria de Maria da Natividade Abreu da Costa e Irene Alves de Deus, e Laqueadura tubária: controvérsias éticas, morais, físicas e psicológicas, de autoria de Isabel Cristina Andrade Sirqueira, Ana Lúcia Araújo Caxico, Irene Alves de Deus, e Mary Célia Silva Santos.

Nesta gestão, ainda, foi iniciado o primeiro ante projeto de Reconstituição Histórica da Enfermagem em Sergipe, que naquele momento não foi levado a efeito, só tendo-se iniciado em 1993, através de um projeto do Departamento de Enfermagem e Nutrição.

Vale ressaltar aqui a dificuldade que se tem tido de trabalhar este resgate histórico, em vista de muito do acervo da ABEn ter-se incorporado ao acervo da Escola de Auxiliares de Enfermagem Augusto Leite, pela estreita ligação que sempre houve entre as duas diretorias, tendo este acervo sofrido uma grave perda quando da transferência das dependências daquela Escola para um novo prédio, sendo então, muita coisa destruída como "coisa velha". 
Outra perda foi motivada pelas condições precárias da sede adquirida em 1990, fato observado quando da transferência do acervo para a nova sede, tendo-se então verificado a deterioração de muitos livros e pastas, sem condições de recuperação. Além disso, existe um livro de atas, única fonte documental do período de 29.09.1970 a 31.01.1985, que não foi localizado durante o período da pesquisa.

Em todos os períodos pesquisados, entretanto, seja nos registros ou nos depoimentos, há sempre a luta pela aquisição da sede, a dificuldade de aumento do quadro de sócios, a continuidade das lutas, a participação nos trabalhos e eventos locais, regionais e nacionais, o incentivo à produção científica, tendo-se registrado em 1997 e 1999 mais dois premios a nível nacional por trabalhos apresentados em Congresso, e a integração aos objetivos da categoria e dos trabalhadores em geral.

Após tantas lutas, finalmente em, 26 de agosto, de 1998, na gestão da presidente Prof. Alzira Maria D'avila Néri Guimarães, a ABEn Sergipe estabelece com a Prefeitura Municipal de Aracaju um convênio de prestação de serviços que lhe possibilitaria não só o aumento de seu quadro de sócios, já que todos os prestadores de serviço seriam sócios da ABEn Sergipe, mas também, em conseqüência disto, na gestão da presidente Prof. Cássia Maria Macedo Silva Faro foi possivel adquirir e manter até hoje sua sede própria, inaugurada em 12 de maio de 2000.

E, assim, segue até hoje, a ABEn Sergipe, pequena em dimensões matemáticas, mas grandiosa em luta, resistência, perseverança, força, seriedade e qualidade naquilo que se propõe e/ou que sente necessário empreender.

ABSTRACT: This work outlines the facts that contributed for the creation of the Brazilian Association of Nursing in Sergipe. It reports the trajectory, contributions and main accomplishments of ABEN in that state, pointing out its participation in the foundation and organization of services and institutions. The study also mentions the difficulties faced by ABEn-Sergipe, but mainly, it emphasizes the struggle of the association for maintaining its principles, its role in the social and cultural organization of the syndicate, and the availability of the nursing service for the community.

KEYWORDS: ABEn-Sergipe, history of nursing

RESUMEN: El trabajo relata los hechos que contribuyeron para la creación de la sección Sergipe de la ABEn, su trayectoria, su aporte para la formación de la imagen cultural de la profesión en la sociedad de Sergipe y sus principales realizaciones, tales como participación en la creación y organización de servicios e instituciones. Trata también de sus dificultades, pero -principalmentesobre la lucha constante para seguir manteniendo sus principios, su papel en la organización social y cultural de la clase y en el servicio prestado a la comunidad.

PALABRAS CLAVE: ABEn Sergipe, historia de la Enfermería

\section{REFERÊNCIAS BIBLIOGRAFICAS:}

ABEn-SE. Atas. Aracaju: Associação Brasileira de Enfermagem-Seção Sergipe. 1958 a $1970 ; 1985$ em diante

CARVAlHO, A. C. de. Associação Brasileira de Enfermagem: documentário 1926-1976 Brasília: ABEn, 1976. 514p.

SANTOS, L. A. Evolução histórica da Enfermagem em Sergipe. Conferência proferida na Semana comemorativa dos 20 anos do Curso de Enfermagem da UFS. Aracaju, 13 maio 1996. Não publicado. 
VIEIRA, M. J. Imagem cultural e motivação na escolha da Enfermagem. 1998. 174 p. Tese (doutorado). Escola de Enfermagem de Ribeirão Preto / USP, Ribeirão Preto

VIEIRA, M. J. O tempo e a imagem cultural da Enfermagem em Sergipe. In: $1^{\circ}$ Colóquio LatinoAmericano de História de Enfermagem. Rio de Janeiro, Resumos... Rio de Janeiro: EEAN/Nuphebras, 2000. 1 disquete

VIEIRA, M. J.; SANTOS, L. A.; LIMA, W. R. Reconstituição histórica da Enfermagem em Sergipe. In: $1^{\circ}$ Colóquio Latino-Americano de História de Enfermagem, 1., 2000, Rio de Janeiro. Resumos... Rio de Janeiro: EEAN/Nuphebras, 2000. 1 disquete.

VIEIRA, M. J. Resgate histórico da Associação Brasileira de Enfermagem-Seção Sergipe. Conferência proferida durante a $62^{a}$ Semana Brasileira de Enfermagem. Aracaju: Associação Brasileira de Enfermagem - Seção Sergipe, 15 maio. 2001. 